\title{
8 \\ rommhalina \\ A ausência Freireana nos programas de formação de professores em nível de graduação no Brasil
}

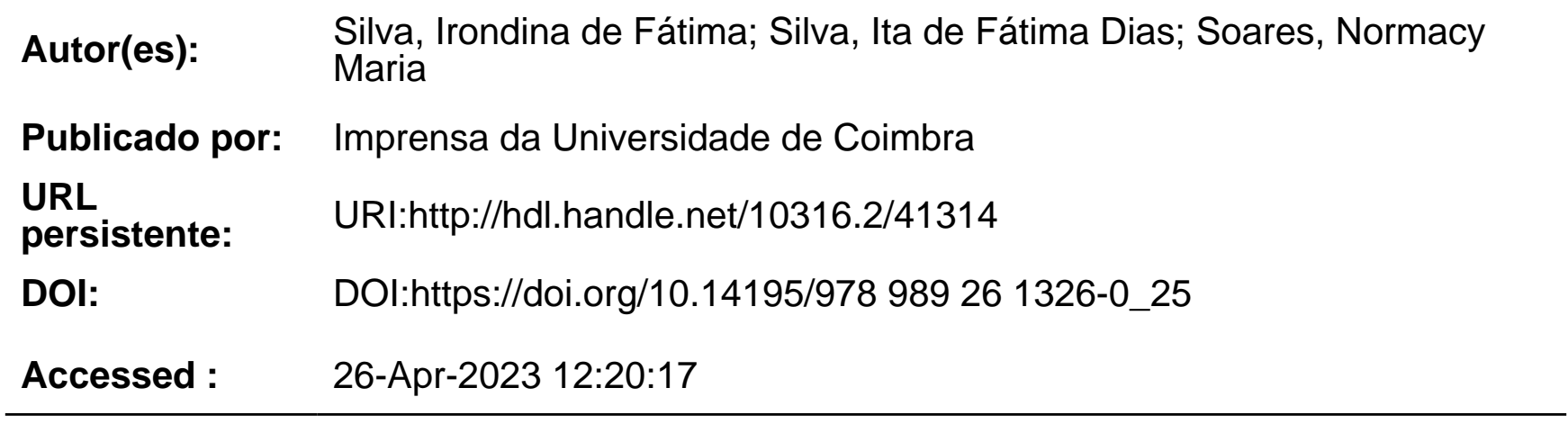

A navegação consulta e descarregamento dos títulos inseridos nas Bibliotecas Digitais UC Digitalis, UC Pombalina e UC Impactum, pressupõem a aceitação plena e sem reservas dos Termos e Condições de Uso destas Bibliotecas Digitais, disponíveis em https://digitalis.uc.pt/pt-pt/termos.

Conforme exposto nos referidos Termos e Condições de Uso, o descarregamento de títulos de acesso restrito requer uma licença válida de autorização devendo o utilizador aceder ao(s) documento(s) a partir de um endereço de IP da instituição detentora da supramencionada licença.

Ao utilizador é apenas permitido o descarregamento para uso pessoal, pelo que o emprego do(s) título(s) descarregado(s) para outro fim, designadamente comercial, carece de autorização do respetivo autor ou editor da obra.

Na medida em que todas as obras da UC Digitalis se encontram protegidas pelo Código do Direito de Autor e Direitos Conexos e demais legislação aplicável, toda a cópia, parcial ou total, deste documento, nos casos em que é legalmente admitida, deverá conter ou fazer-se acompanhar por este aviso.

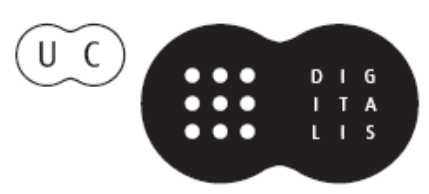




\title{
25. A AUSENCIA FREIREANA NOS PROGRAMAS DE FORMAÇÃO DE PROFESSORES EM NÍVEL DE GRADUAÇ ÃO NO BRASIL
}

\author{
Irondina de Fátima Silva ${ }^{127}$ \\ Ita de Fátima Dias Silva ${ }^{128}$ \\ Normacy Maria Soares 129
}

\begin{abstract}
Resumo
Este texto trata-se de um estudo sobre a concepção pedagógica progressista libertadora de Paulo Freire, e a sua ausência, nos currículos dos cursos de formação de professores, bem como refletir sobre os saberes necessários à prática educativa, uma sugestão de Paulo Freire para o exercício da docência. As sugestões de Paulo Freire aos docentes estão registradas em um de seus livros, escrito especialmente para os educadores brasileiros, "Pedagogia da Autonomia: saberes necessários a prática educativa" (2010), publicado um ano antes do seu falecimento, em 1996. As suas principais ideias são:
\end{abstract}

127 Graduada e Mestre em Educação pela Universidade Federal de Goiás. Professora Titular no Centro Universitário de Mineiros - UNIFIMES - Goiás/Brasil, respondendo atualmente pela Diretoria da Pós-graduação e Expansão.

128 Graduada e Mestre em Educação pela Universidade Federal de Goiás. Professora Titular no Centro Universitário de Mineiros - UNIFIMES - Goiás/Brasil, respondendo atualmente pela Reitoria.

129 Graduada em Pedagogia - UNIFIMES. 
reflexões a respeito da relação docente e discente na sua opinião, não há docência sem discência. Na sequência pontua reflexões sobre o ato educativo que, segundo ele: o ensinar não é transferir conhecimento, e, na última parte traz um debate sobre o ensinar como uma especificidade humana. A concepção de educação progressista libertadora foi criada nos anos 50 e 60 por Freire, como uma possibilidade de alfabetizar os milhões de brasileiros analfabetos oprimidos daquela época. Conhecer a concepção progressista libertadora exigiu um estudo sobre a vida de Freire, uma vida dedicada a educação. A metodologia utilizada se referiu a um estudo bibliográfico.

\section{Abstract}

This paper addresses the liberating progressive pedagogical concept of Paulo Freire, and its absence in the curricula of teacher education courses. It also proposes a reflection on the necessary knowledge to the teaching practice, a suggestion of Paulo Freire for the exercise of teaching. Paulo Freire's suggestions to teachers are registered in one of his books, which was specially written for Brazilian educators, "Pedagogy of Autonomy: knowledge needed for educative practice" (2010), first published a year before his death, in 1996. His main ideas are: reflection about the relationship between teacher and student - in his opinion, there is no teaching without learning. Therefore, Freire point out reflections about the educative act - according Freire's ideas, teaching is not about transferring knowledge. In the last part of the book, there is a debate about teaching as a human specificity. The foundations of the liberating progressive pedagogical concept were developed in 50's and 60's by Freire as a possibility to alphabetize millions of Brazilians oppressed that time. To understand the liberating progressive pedagogical concept required a study of Freire's life, a life devoted to education. The methodology of this study is characterized by a bibliographic analysis. 


\section{Introdução}

A concepção de Paulo Freire no contexto educacional brasileiro e mundial tem como referência a sua obra clássica conhecida pelos educadores do mundo inteiro "Pedagogia do Oprimido". Freire, como era conhecido, foi registrado com o nome de Paulo Reglus Neves Freire, nome que segundo ele nunca pegou, nasceu no dia 19 de setembro de 1921, em Recife - PE, falecendo em 02 de maio de 1997, com 75 anos, em São Paulo.

Era um homem de origem de família simples, do interior do nordeste, foi alfabetizado pela sua mãe, no fundo do quintal de sua casa, utilizando de um graveto escrevia as palavras no chão. Frequentou escolas simples, e no $2^{\circ}$ grau iniciou sua carreira profissional como professor. Desde então, nunca mais parou, carreira que só a morte foi capaz de interrompê-la aos 75 anos de idade. Foi um educador incansável, e descobriu que a educação é política, assim como a política é educação.

Teve como projeto maior de sua vida trabalhar em prol da libertação do povo brasileiro oprimido, e acreditava ser a educação o melhor caminho para que a libertação se efetivasse. Neste sentido, dedicou seus estudos no intuito de elaborar uma proposta de educação de jovens e adultos, que alfabetizasse, e conscientizasse os trabalhadores, concedendo-lhes o direito de tomar consciência da condição de exploração em que a maioria deles vivia naquela época numa condição de oprimido. Chegou a colocar em prática a sua proposta de alfabetização de adultos numa região de cortadores de cana no sertão do Rio Grande do Norte município de Angicos, onde em apenas 45 dias alfabetizou 300 trabalhadores rurais.

Os trabalhadores, além de aprenderem a ler tomaram consciência das suas condições de explorados pelos proprietários rurais. Neste período o Brasil tinha um alto índice de analfabetismo e como a sociedade estava em processo de transição saindo de uma 
economia rural manual para industrial precisava muito de pessoas escolarizadas. A proposta de Alfabetização de Adultos foi bem aceita pelo Presidente da República da época, ocasião em que Freire foi convidado a fazer parte do Ministério da Educação e implantá-la nos diferentes municípios brasileiros.

Porém, em função da proposta ir além da leitura pela decodificação (meta do governo) tendo um cunho de transformador, ele foi interrompido pelo Golpe Militar que culminou com a Ditadura em 1964. Nesse contexto Paulo Feire foi considerado subversivo, foi preso, expulso do país e viveu exilado entre o período de 1964 a 1979.

No exílio juntou-se a outros brasileiros adeptos as suas ideias e continuaram trabalhando o projeto de alfabetização de jovens e adultos, onde prestou relevantes serviços como no Chile e Suíça. Nesses países, Freire conseguiu contribuir com a redução do índice de analfabetismo com a implantação do seu projeto de alfabetização por meio da conscientização, tirando as vendas dos olhos de trabalhadores, o que culmina na emancipação, libertação e autonomia do cidadão.

Paulo Freire volta ao Brasil no início dos anos 80, momento em que retoma suas atividades num enfoque transdisciplinar atuando em diferentes áreas da Educação. Foi Secretário Municipal da Educação na cidade de São Paulo, atuou como professor Universitário, palestrante e orientou vários mestrandos e doutorandos.

Freire, ao propor o modelo de alfabetização de adultos e a concepção de uma educação progressista libertadora, fez uma síntese das correntes do pensamento filosófico de sua época, pensamentos esses que foram cruciais na fundamentação da sua concepção pedagógica como: existencialismo cristão, fenomenologia, dialética hegeliana e materialismo histórico. Essa visão, somada ao seu talento de escritor ajudou-o a conquistar um amplo público de educadores, cientistas sociais, teólogos e militantes políticos, quase sempre ligados a partidos de esquerda pelo mundo. 
A partir de suas primeiras experiências no Rio Grande do Norte, em 1963, quando alfabetizou 300 trabalhadores rurais em 45 dias, Paulo Freire desenvolveu um projeto inovador de educação. Enquanto profissional escolheu trabalhar como professor numa escola de $2^{\circ}$ grau lecionando língua portuguesa. Em 1946 foi indicado ao cargo de diretor do departamento de Educação e Cultura do Serviço Social do Estado de Pernambuco, onde iniciou o trabalho com analfabetos pobres e aproximou-se do movimento de teologia da educação onde tudo começou. Posteriormente culminando com a proposta de alfabetização de adultos.

Sabe-se que o pensamento pedagógico freireano, naquele contexto sócio-histórico e político era fundamental para contribuir com a redução do elevado índice de analfabetismo do país, o que era um dos problemas da educação brasileira. Contudo, a proposta nem se efetivou enquanto instrumento de redução do analfabetismo, nem fez parte e não influenciou nos currículos dos cursos de formação de docentes, principalmente nos cursos de pedagogia, durante a reforma universitária de 1969, conforme a análise do parecer do Conselho Federal de Educação nº. 252/1969.

Quanto a essas questões, segundo Ruiz (2011), falar do papel de educadores e educadoras na sociedade atual demanda entender como esse foi se construindo através do caminhar da educação brasileira. Nas linhas dessas ideias Gadotti (1998), reforça a discussão e chama a atenção para o problema, a partir da análise histórica vivenciada no Brasil em 1969 - período da então ditadura militar.

Para o autor os currículos dos cursos de formação de professores foram reformulados para atender o regime militar, contexto esse que nos remete a pensar em um educador passivo, apolítico, técnico sem preocupações sócio políticas, com agir desvinculado da realidade na qual se inseria.

Entende-se então, a partir do contexto apresentado por Gadotti (1998), que a filosofia Freireana não influenciou e nem foi utilizada 
nos cursos de formação de professores no Brasil, uma vez que o cenário econômico e político, marcado pelo capitalismo industrial, necessitava de profissionais que atendessem as novas demandas do mercado. Nesse sentido, os cursos de formação foram reformulados para atender uma concepção tecnicista, uma necessidade da nova economia em ascensão no país.

Além disso, a maioria dos docentes em exercício nas universidades e nas escolas que formaram e continuam formando professores, mesmo com a divulgação dos princípios freireanos, não conhecem o pensamento, a proposta e as práticas pedagógicas de Paulo Freire. Discutir o pensamento de Paulo Freire hoje, nos cursos de formação de professores, requer entender o que diz Ruiz (2011), que no momento atual é de profundas transformações e muitas mudanças e inovações tecnológicas, que deixam o país sem saber qual caminho trilhar. A sociedade encontra-se em crise na qual somos conduzidos a repensar nossos valores e atitudes.

Nesse contexto de incertezas o papel do profissional da educação tem que ser repensado.

[...] faz-se mister que o professor se assuma enquanto profissional do humano social e político, tomando partido e não sendo omisso, neutro, mas sim definido para si de qual lado está, pois se apoiando nos ideais freireanos, ou se está a favor dos oprimidos ou contra eles. Posicionando-se este profissional não mais neutro, pode ascender a sociedade usando a educação como instrumento de luta, levando a população a uma consciência crítica que supere o senso comum, todavia não o desconsiderando. Ruiz (2011, p. el).

O povo, tomando consciência desse saber, poderá ter condições de se proteger contra a exploração das classes dominantes, organizando-se para a construção de uma sociedade menos excludente e mais democrática. A conscientização da classe explorada 
só muda a partir de uma ação social organizada; nenhuma decisão ou conscientização nasce espontaneamente. Sendo assim:

Educadores e educandos precisam engajar-se social e politicamente, percebendo as possibilidades da ação social e cultural na luta pela transformação das estruturas da sociedade classista. Para isso, antes de tudo necessitam conhecer a sociedade que atua e o nível social e econômico de seus alunos e alunas. Ruiz. (2003, p. 56)

Casando a concepção de Ruiz (2011) com a de Freire (2010), entende-se que: todo ato educativo é uma ação política; nenhum professor é neutro. O espaço da escola não é algo neutro, ao contrário, é um espaço em que os embates políticos travados e a luta de classe se fazem presentes.

O professor, ao reconhecer que a educação é política e que também é político deve se perguntar: Que tipo de política estou fazendo em classe? Estou sendo um professor a favor de quem? Contra ou a favor de quem estou educando? Como devo conciliar minha prática de ensino como opção política? Para esclarecer essas interrogações, Freire explica:

Agora descobri a realidade da sociedade e minha opção é em favor de uma educação libertadora. Sei que o ensino não é alavanca para a mudança ou a transformação da sociedade, mas sei que a transformação social é feita de muitas tarefas pequenas e grandes, grandiosas e humildes.

Freire (2010) afirma, estou incumbido de uma dessas tarefas. Sou um humilde agente da tarefa global de transformação. (...), descubro isso, proclamo isso, verbalizo minha opção. A questão agora é como por minha prática ao lado do meu discurso. Isto é, como posso proclamar meu sonho de libertação, e, no dia seguinte, ser autoritário na relação com os estudantes em nome do rigor (p.60). 
Não se pode mais falar de alguma coisa sem propor mudança, é preciso que cada um no seu espaço social construa essa mudança, em especial o professor, que muitas vezes não sabe qual é o seu papel no contexto da educação às vezes passam o tempo em busca de culpados pela má qualidade do ensino, esquecendo-se de cumprir com responsabilidade o seu papel enquanto educador, que trabalha com a formação do ser humano.

Como bem disse Freire (2010) sou um humilde agente da tarefa global de transformação, resta-nos saber e ter consciência do nosso papel enquanto agentes da educação e fazer a nossa escolha e trabalhar nessa perspectiva de transformação ou continuar reproduzindo o status-quo que interessa ao sistema vigente no país.

Com o objetivo de conhecer os princípios básicos propostos por Paulo Freire no ato educativo entre o educador e o educando numa ação transformadora, ele escreve um dos seus últimos livros refletindo sobre a Pedagogia da Autonomia, construída entre o educador e o educando numa relação dialógica no espaço de aprendizagem. O qual ele acredita que é o espaço de construção do conhecimento.

Nesta obra ele faz reflexões e aponta caminhos aos educadores, buscando incentivá-los a optarem por uma prática voltada para uma pedagogia da autonomia que possibilite a libertação, a construção do conhecimento entre professor-aluno numa relação dialógica pautada na ética universal.

Freire (2010) sublinha esta responsabilidade igualmente àqueles e aquelas que se acham em formação para exercê-la... Educadores e educandos não podemos, na verdade, escapar à rigorosidade ética... É por esta ética inseparável da prática educativa, não importa se trabalhamos com crianças, jovens ou com adultos, que devemos lutar. E a melhor maneira de por ela lutar é vivê-la em nossa prática, é testemunhá-la, vivaz aos educandos em nossa relação com eles (p.15-16). 
A proposta educativa de Paulo Freire requer do educador uma postura prática pautada na ética. Isto vai de encontro a qualquer tipo de alienação, conhecido como método tradicional. Neste sentido, é relevante discutir no próximo item quais são os saberes necessários à prática educativa na qual o autor acredita e sugere aos educadores no final do século XX e início do século XXI.

\section{Paulo Freire e os saberes necessários à prática educativa docente}

Pedagogia da Autonomia: Saberes necessários à prática pedagógica docente, de Paulo Freire traz reflexões bem como sugere quais são os requisitos básicos imprescindíveis que identificam o perfil do professor segundo a sua filosofia.

Dentro da concepção Freireana, o primeiro princípio a ser adotado pelo professor no exercício da docência é a ética. E a ética que ele defende é a "ética universal", por ser ele frontalmente contra qualquer ato que quebre o princípio de igualdade, como distinção, exclusão, restrição ou preferências, motivadas por raça, cor, sexo, idade, trabalho, credo religioso, ou convicções políticas, bem como atos de agressão contra os animais e à própria natureza em qualquer parte do planeta.

Nesta linha de pensamento Freire defende e demonstra o respeito para com os seres vivos de qualquer espécie, e crê na dignidade, na fraternidade, na justiça social. Consequentemente é contra a violência, a opressão, a fome, a miséria, a exploração do trabalho, e a exclusão, social, a antidemocracia, a dominação, a alienação, o desemprego e a discriminação racial.

Segundo ele não se ensina ética com palavras e sim com exemplos de vida. O que Freire (2010) quis mostrar foi que, antes de "ensinar ética, o professor deve vivê-la". Em sua opinião os ensinamentos e 
o aprendizado sobre ética só acontecem através do exemplo corporificado do professor, não há como ensinar ética por meio de palavras, uma vez que o verdadeiro ensinamento acontece através da socialização humana, em que uns aprendem com os outros à medida que vão se interagindo no mundo.

A ética, na concepção de Paulo Freire, (2010) é a base fundamental e necessária em todos os relacionamentos. Acredita-o que, se vivenciada pelos povos universalmente no dia a dia, o mundo encontraria seu equilíbrio natural. Afinal, se o planeta está em processo de degradação, isso se deve ao ser humano, o único com capacidade para modificar a natureza, seja a seu favor ou contra ele mesmo.

Segundo Freire, (2010) estamos vivendo em uma época de crise de ética mundial, e nos perguntamos se ainda há esperança de reverter o quadro dos valores éticos e morais? A final, bem diz Paulo Freire: não temos a dimensão do que somos capazes de fazer, e o que fazemos às vezes gera resultados que não controlamos.

É com base nos princípios da Ética Universal que Paulo Freire propõe as necessidades básicas a pratica pedagógica do professor progressista libertador sugerida no seu livro Pedagogia da Autonomia.

As primeiras necessidades básicas descritas e sugeridas por ele dizem respeito a rigorosidade metódica, a pesquisa, ao respeito aos saberes do educando, não há como ensinar sem a existência desses três pontos seja por parte do professor ou do educando.

Freire (2010) acredita que o ato de educar exige transmissão do conhecimento, porém de uma forma democrática e crítica. A condição de aprendizagem do educando, no decorrer do processo, vai orientar o professor, no percurso de criação e autocrítica de forma instigadora, rigorosa, porém, com humildade e persistência, com o propósito de se atingir o objetivo almejado.

No entender de Paulo Freire (2010) 'não há ensino sem pesquisa e pesquisa sem ensino. A pesquisa, quando busca conhecimento, 
produz um aprendizado mútuo, uma vez que o professor aprende, para depois ensinar.

Freire na sua concepção filosófica de educação acredita e propõe aos adeptos da sua teoria a assunção de uma prática pedagógica em que prima pelo rigor metodológico, do ensino e da pesquisa no cumprimento da tarefa de educar. Por acreditar que a maioria dos professores não se adequa nesta forma mútua de aprendizagem, porque não são preparados ou às vezes a sua opção política não condiz com a sua proposta de educação, preferem defender a ideologia do dominador.

Alerta os educadores para o risco de se praticar em sala de aula a chamada educação bancária, aquela em que o professor é o dono do conhecimento, portanto a sua tarefa consiste em depositar esses conhecimentos no aluno como se deposita dinheiro no banco. Conhecimentos os quais os professores acreditam serem eles os melhores para os seus alunos, e que na maioria das vezes são carregados de ideologias enganosas que visam à manutenção do status quo, que representam e reproduzem os interesses da classe dominante opressora.

A pesquisadora Argentina Nidelcoff (1994) reforça o que diz Freire quando no seu trabalho sobre a realidade da escola pública na Argentina e no perfil do professor da escola pública naquele país, deparou com dois tipos de professores: o primeiro foi denominado de professor policial e o segundo de professor povo.

O professor policial de Nidelcoff (1994) tem o mesmo perfil do professor bancário, citado por Freire (2010), é autoritário, não respeita os conhecimentos que o aluno traz consigo do seu ambiente social e familiar, só ele sabe, avalia seus alunos de forma temporal. Em contrapartida, o professor povo é o que Freire chama de educador, aquele que acredita no seu educando, estabelece com ele uma relação de diálogo, os seus ensinamentos partem do contexto do aluno, e junto com ele constrói o conhecimento numa interação: 
Nidelcoff (1994) questiona: Afinal, quais são os objetivos do professor povo? Trabalha pela libertação do povo começa por tomar como objetivo central e real de sua ação educadora. Frente aos seus alunos, este objetivo central poderia ser definido da seguinte maneira: Ajudar as crianças a se desenvolverem como seres capazes de liberar-se das estruturas opressivas da sociedade atual (p.29).

A preocupação do professor povo ou progressista/libertador é despertar no aluno a consciência crítica. Esse processo inicia especialmente quando o indivíduo descobre a sua ingenuidade em relação às coisas que lhes passam despercebida por falta de consciência crítica. É a partir da descoberta dessa ingenuidade que nasce a curiosidade.

É, portanto, a partir dessa curiosidade ingênua que o processo crítico se inicia, mas ele não ocorre de forma natural. Nesse sentido, uma das tarefas precípuas da prática educativa de Paulo Freire é exatamente o desenvolvimento da curiosidade crítica, insatisfeita, indócil que precisa ser despertada nos alunos a partir do contexto em que eles vivem numa ação conjunta entre eles e o professor Freire (2010).

A proposta de Paulo Freire nos leva do encantamento para a angústia, pois, enquanto a prática educativa soa para ele mesmo que flui naturalmente do seu íntimo, é um testemunho rigoroso de decência e de pureza, para nós é um grande desafio a vencer, vivenciar e praticar essa teoria implica no professor uma decisão política, considerando que nenhum conhecimento repassado ou construído com o aluno é neutro. Além da decisão política do professor, ele precisa definir de que lado quer ficar, quais são os interesses a defender e estar preparado, conhecer as bases sociológicas que fundamentam a concepção freireana, desde a sua proposta e projetos, bem como suas experiências.

Ao nos dizer que ensinar exige corporificação das palavras, pelo exemplo, induz aos educadores uma constante avaliação sobre seus 
atos, considerando que todos os dias o professor é assediado pelos meios de comunicação de massa, os maiores e mais poderosos concorrentes do professor: TV, internet, celulares, sem falar naqueles que muitas vezes nem conhecemos, mas com os quais a maioria dos educandos estão familiarizados. Daí se justifica a necessidade e a importância da construção de um bom referencial de formação nos primeiros anos vida da criança, na verdade nem sempre acontece e se percebe que a sociedade mudou seus valores, constatando, assim, uma crescente escassez de bons princípios morais no cidadão brasileiro em todas as idades.

Diante do exposto, não podemos sequer nos permitir questionar se vale a pena continuar acreditando na escola e no professor como elementos essenciais para a sociedade e dignos de credibilidade. A bem da verdade, todo ser humano deve cumprir seu papel na sociedade e, de maneira especial, o professor, que atua numa instituição responsável pela formação humana. Mais que nunca tem que ser o exemplo! Por isso, os seus ensinamentos precisam ser vividos e não somente transmitidos. $\mathrm{O}$ bom professor não fala de princípios morais, ele os ensina por meio de suas práticas corporificadas.

O professor na concepção de Freire (2010) deve vivenciar a ética universal, inclusive na maneira de se vestir e se comportar, pois a melhor forma de ensinar é através do exemplo.

E entre o testemunho de dizer e o de fazer, o mais forte é o do fazer porque este tem ou pode ter efeitos imediatos. O pior, porém, para a formação do educando é que, diante da contradição entre fazer e dizer, o educando tende a não acreditar no que o educador diz. Se agora ele afirma algo, ele espera a próxima ação para detectar a próxima contradição. E isso corrói o perfil do educador que ele mesmo vai fazendo de si e revela aos educandos. Freire (1994).

A esse respeito Freire (1994) ainda diz que o pior de tudo é quando "Se esta coisa que está sendo proclamada, mas ao mesmo 
tempo, tão fortemente negada na prática, fosse realmente boa, não seria apenas dita, mas, vivida" (p. 76).

Não há o que comentar, o autor explicou que o exemplo é muito forte para a criança que busca se espelhar no adulto e em especial aquelas pessoas que cuidam diretamente da sua educação como os pais e professores. Atenção! Muita atenção! O que vivemos e falamos para as nossas crianças elas aprendem exatamente, o que nós ensinamos a elas e, sobretudo, nos exemplos. Afinal, qual está sendo o nosso referencial de vida repassado aos jovens e crianças na atualidade? Não adianta cobrar delas no futuro aquilo que não ensinamos hoje, portanto, cuidado, pais e professores.

Ensinar também exige do professor consciência do inacabado, o homem é um ser em constante processo de construção e aprendizado, as coisas mudam sempre e precisamos mudar o nosso jeito de ser com elas. Isso exige que o professor e o aluno encontrem-se nessa marcha de socialização e interação, buscando aprender juntos, procurando fazer uma reflexão crítica constante sobre as práticas realizadas nas atividades, a fim de irem inovando os seus conhecimentos. É tarefa do professor aprender sempre e despertar no aluno essa consciência de formação continuada.

Paulo Freire (2010) proclama que uma das tarefas mais importante na prática educativa crítica é propiciar as condições para que os educandos, em suas relações uns com os outros, em comum com o professor, aprendam através desta experiência profunda, como se assumir enquanto ser social e histórico; como ser presente, comunicativo, transformador, criador e realizador; que tenha capacidade para sentir raiva, mas aprenda simultaneamente como dominar seus impulsos. Mas, acima de tudo, que desenvolva capacidade de amar. $O$ autor desfere uma infinidade de golpes certeiros naqueles que assumem a tarefa de ensinar, e muitas vezes ignoram seus ensinamentos e técnicas que, apesar da simplicidade, de grande valor na prática educativa, expressão da mais absoluta verdade. 
Neste sentido, Freire (2010) acredita que ensinar não é transferir conhecimento, portanto, exige a consciência de que as coisas são inacabadas e o reconhecimento do que somos condicionados. O respeito à autonomia do educando é algo imprescindível no ato educativo, bem como o bom senso, a humildade, a tolerância, o respeito ao saber do educando adquirido na sua realidade, a alegria e a esperança que devem estar muito presentes no ato educativo.

Ensinar exige também a convicção de que a mudança é possível e que nós fazemos parte dela, assim como a curiosidade que instiga professor e aluno a buscarem sempre.

A última parte do livro Pedagogia da Autonomia de Freire (2010) discute o tema e propõe uma série de exigências que considera fundamental a prática pedagógica docente no contexto da temática geral: ensinar é uma especificidade humana e nesse contexto ele considera que o ato de ensinar exige por parte do educador: segurança, competência profissional, generosidade, comprometimento, compreensão de que a educação é uma forma de intervenção no mundo, exige também liberdade e autoridade, tomada de decisões conscientes, saber escutar, reconhecer que a educação é ideológica, exige disponibilidade para o diálogo e, por fim, exige querer bem aos educandos.

Não há como admitir que a relação educador e educando seja fria e sem afetividade. O que não se pode permitir é a interferência da afetividade no cumprimento ético do exercício da docência, mas que ela esteja presente no dia a dia, tornando a relação educador/ educando e o conhecimento algo prazeroso e alegre.

\section{Considerações Finais}

Analisando projetos de cursos de licenciaturas de diferentes instituições brasileiras a época de elaborar e reformular os projetos pedagógicos dos cursos de Licenciatura da instituição em que tra- 
balho percebi que, dentre os projetos pedagógicos que pesquisei, tanto em instituições públicas quanto particulares, só um deles propôs a realização de um seminário integrado no primeiro período direcionado a discutir a proposta pedagógica de Paulo Freire.

Há mais de 20 anos ministro aulas no curso de Pedagogia, e sempre uma ou duas obras de Freire fazem parte das referências bibliográficas das disciplinas sob minha responsabilidade, em especial a obra Pedagogia da Autonomia que considero o livro de cabeceira do professor. Além disso, direciono minhas pesquisas nos cursos de licenciaturas e as orientações de Trabalho de Conclusão de Curso (monografias) para possibilitar aos estudantes uma reflexão sobre a pedagogia Freireana, que ao meu ver foi e continuará sendo uma proposta transformadora, inovadora e possível de ser aplicada em qualquer nível ou modalidade de ensino.

Sabe-se que a história da educação no Brasil foi e vem sendo construída com muitas contradições e sem prioridades. Os professores, a partir de 1996 com a aprovação da Lei de Diretrizes e Bases da Educação Nacional (LDEN), conseguiram a garantia de políticas públicas voltadas para a sua formação em nível superior. A partir da lei o ensino básico, a educação infantil e o ensino fundamental passaram a ter a exigência de contar com profissionais formados no nível superior. Podendo ser admitidos professores de nível médio somente na educação infantil e séries iniciais, na falta de graduados.

A partir da aprovação da LDBEN a formação de professores em nível superior passou a ser uma exigência legal. Eis algumas considerações importantes sobre a formação de professores que merecem destaque:

- Em se tratando dos conceitos e da trajetória educacional no Brasil e da formação de professores, percebe-se que tanto a educação quanto a formação de professores, foi tratada com descaso pelas autoridades. Só a partir da chegada da Família 
Real ao Brasil é que o imperador, preocupado com o seu reinado, inicia o processo de organização da Educação no país.

- O professor, antes da aprovação da LDBEN, ou era um leigo ou normalista em raríssimas exceções, professores com curso superior não havia, assim, para ser professor bastava saber um pouco mais ou ter um nível igual ao do seu aluno. Também por parte do governo não existia nenhuma preocupação com a formação docente.

- Os cursos normais criados nas décadas de 1930 e 1940 não tinham bases sólidas, abriam e fechavam várias vezes.

- O curso de Pedagogia criado em 1939 tinha como preocupação formar técnicos para atender o processo de industrialização. E foram reformulados em 1969 para atender os interesses da ditadura militar.

- A LDBEN representa um marco na conquista pela formação de professores, que agora passa a acontecer em nível superior.

- Paulo Freire, um dos maiores educadores do século XX, era um homem humilde de classe média, fez direito e filosofia, e dedicou sua vida à educação, a sua proposta criada para questionar e lutar contra a opressão vivida pela sociedade naquele momento, por ser contra qualquer tipo de opressão e dominação não foi aceito pela classe dominante que o perseguiu e o expulsou do país durante o regime militar por mais de 15 anos.

- Na década de 1950 e início dos anos 60 surge o projeto de alfabetização de adultos de Paulo Freire numa concepção de educação progressista libertadora, fruto de muito estudo sobre a filosofia de Marx e Engels, baseada no materialismo histórico, existencialismo cristão, somada a vivência da situação em que a sociedade brasileira vivia naquela época, dividida em duas classes sociais distintas. De um lado estava a classe dominante opressora, do outro a classe trabalhadora (a maioria 
da população analfabeta) oprimida, vivendo um momento de transição em que a sociedade tenta sair de uma economia (fechada) voltada para o capital estrangeiro, para uma sociedade aberta e democrática (processo de industrialização).

- A pedagogia do oprimido é aquela em que Paulo Freire acredita que é capaz de ser aplicada em qualquer sociedade capitalista em que existe oprimido e opressor, em que a prática pedagógica do professor consiga, por meio do processo de conscientização dos oprimidos, libertá-los, tirá-los da condição de dominados e oprimidos e torná-los sujeitos ativos, construtores da sua história por meio de uma aprendizagem consciente e autônoma, que seja capaz de contribuir para a transformação da sociedade, tornando-a mais justa, mais humana, com menos desigualdades sociais.

- No Brasil, a partir do período colonial, constatou-se a presença de três correntes de tendências pedagógicas, e cada uma delas representam os interesses educacionais vigentes na época, e dentro de cada uma dessas correntes existem as tendências que representam a educação em cada período histórico da sociedade e educação brasileira.

A primeira corrente abriga as tendências pedagógicas liberais, e nessa corrente estão as tendências pedagógicas: a) Liberal Tradicional, Liberal Renovada Progressivista, Tendência Renovada, Não Diretiva e a Liberal Tecnicista.

Essa corrente defende e representa o maior período da história da educação brasileira, surge com a educação Jesuítica e vai até os anos 60, embora surjam outras tendências depois destas; constata-se que essa corrente continua muito presente na educação ainda no século XXI. Considerando que a sociedade brasileira continua capitalista, dividida em classes sociais distintas com interesses antagônicos, em que prevalecem os interesses da classe dominante. 
A outra corrente de tendências pedagógicas surge no final da década de 1950 e início dos anos 60 é a Tendência Progressista, e com ela nascem outras tendências: Progressista libertadora, Progressista Libertária e a Crítico-Social dos Conteúdos. Essas tendências representam um avanço na educação, e vão contra os princípios da Educação tradicional. Tem em comum a proposta de uma educação que visa à libertação do homem de qualquer tipo de opressão por meio de uma educação conscientizadora.

Percebe-se que as ideias dessas tendências estão presentes na ação isolada de algumas instituições, organizações e Universidades, porém a legislação brasileira e as diretrizes curriculares defendem uma proposta de educação ainda tradicional e neoliberal.

Tratando-se da formação de professores constatou-se que a corrente progressista libertadora não influenciou nos cursos de formação de professores porque esses cursos foram reformulados em 1969 para atender os interesses da ditadura, numa concepção tecnicista. Vale ressaltar que a maioria dos professores em exercício nos cursos de formação no início deste século foi formada nesses cursos e eles continuam formando outros professores.

A terceira corrente é a tendência pedagógica interacionista, criada depois da aprovação da LDBEN 9394/96 para atender os interesses do projeto neoliberal.

A partir do conhecimento sobre os saberes necessários a prática pedagógica docente proposta por Paulo Freire na obra Pedagogia da Autonomia; dedicada aos professores, somado ao conhecimento das suas bases filosóficas sociológicas, sua trajetória de vida na educação, seu compromisso com uma educação para a transformação, por meio da conscientização e libertação dos oprimidos, e ainda vivendo numa sociedade em que uma grande parcela dela vive marginalizada e explorada; verifica-se que a sua teoria progressista libertadora que não foi criada de maneira estática, é plenamente possível de ser aplicada na educação deste século com possibilidades de melhorias na educação. 
Foi uma proposta criada e que poderá ser implementada em qualquer época, inclusive numa sociedade onde existe exploração. Tal possibilidade é respaldada a partir da prática e experiência vivenciada em vários outros países, desde que adaptada a cada realidade e momento.

Se os cursos de formação de professores adotassem a teoria de Paulo Freire na formação dos professores, aí sim, os futuros professores sairiam das Universidades preparados para uma educação para a transformação. Na sua concepção os professores antes de assumir a docência deveriam ter consciência de que: ensinar exige rigorosidade metódica, criticidade, pesquisa, respeito aos saberes do educando, estética e ética, corporificação das palavras pelo exemplo, exige risco, aceitação do novo e rejeição a qualquer tipo de discriminação, reflexão crítica sobre a prática e reconhecimento da identidade cultural.

A prática educativa exige a compreensão de que o professor não é um mero transmissor de conhecimento, e que ele deve estabelecer uma relação recíproca entre o aprendente e o ensinante, visando um aprendizado coletivo. Ensinar exige bom senso do educador, humildade, tolerância e luta em defesa dos direitos dos educadores, e compreensão da realidade, exige alegria, esperança e a convicção que a mudança é possível.

$\mathrm{O}$ ato educativo exige curiosidade, segurança, competência profissional, comprometimento e compreensão de que a educação é uma forma de intervenção no mundo. Ensinar é reconhecer que a educação é ideológica e o professor precisa saber escutar e querer bem o seu aluno; na concepção de Freire só é possível uma educação para a transformação por meio de uma prática educativa que conduza o educando à sua libertação, por meio da conscientização que leva à emancipação do cidadão tirando-o da condição de oprimido, concedendo-lhe o direito à cidadania plena. 


\section{Referências bibliográficas}

Freire, P. (1987). Pedagogia do Oprimido ( 17a ed.). Rio de Janeiro: Paz e Terra.

Freire, P. (1994). Professora, Sim, Tia, Não: Cartas a quem ousa ensinar. São Paulo: Olho D' água.

Freire, P. (2000). Educação como prática de liberdade: a sociedade brasileira em transição (24a ed.). Rio de Janeiro: Paz e Terra.

Freire, P. (2010). Pedagogia da Autonomia: Saberes necessário a prática educativa. São Paulo: Paz e terra.

Nidelcoff, M. T. (1994). Uma escola para o povo (37a ed., J. Oliveira, Trad). São Paulo: Trevisan.

Ruiz, M.J.F (2003). O papel Social do professor: Uma contribuição da filosofia da Educação e do Pensamento freireano à formação do professor. Revista Ibero Americana de Educación, 33 (pp. 55-70). Recuperado de http://rieoei.org/ rie33a03.PDF

Gadotti, Moacir. (1998). Pedagogia da Praxis (2a ed.). São Paulo: Cortez Editora.

Brasil. Ministério da Educação. (2011). Lei de Diretrizes e Bases da Educação Nacional. <http.//www.planalto.gov.br/ccivil_03/Leis/L9394.htm> Acesso em 22 de junho 2011. 